\title{
On the locus of the Tulving retrograde amnesia effect
}

\author{
ARTHUR D. FISK \\ University of Illinois, Champaign, Illinois 61820 \\ and \\ DELOS D. WICKENS \\ The Ohio State University, Columbus, Ohio 43210
}

\begin{abstract}
Tulving's retrograde amnesia effect due to a "priority" item was investigated to determine the locus of the effect, whether in the encoding, storage, or retrieval process. The usual effect was eliminated by use of a semantic orienting task (Hyde \& Jenkins, 1973), implying an encoding deficiency.
\end{abstract}

In memory and learning tasks, where a unique item is placed within a list of similar items, the ability to learn the unique item is increased relative to the similar items. The unique item is said to be isolated. The cause of this phenomenon was first examined by von Restorff in 1933 and has subsequently come to be called the von Restorff effect.

An examination of the von Restorff literature (see Wallace, 1965, for a review) reveals three major ways of isolating list items: (1) A different type of physical presentation, relative to the other list items, can be used for the item that is to be isolated. For example, one item in the experimental list may be printed in red, while the remaining items may be black. (2) Semantic manipulation is another isolation technique. As an example, if the control list contains all common nouns, the experimental list may be produced by replacing one of the words with the name of a famous person. (3) A third isolation method requires the subjects in the experimental condition to perform a different psychological operation on the to-be-isolated item than the control subjects. For example, an item can be given priority (and therefore isolated) by requiring subjects to look for and remember a word from a certain taxonomic category.

The latter isolation technique appears to be the most advantageous for experimental use. With this method the experimenter has maximum control over the effect of isolation. Any item is a possible candidate for isolation, and the control group is required to learn the same list items. A direct comparison of conditions

Portions of this paper were presented at the annual meeting of the Midwestern Psychological Association, Chicago, Illinois, May 4-6, 1978. Requests for reprints should be sent to Arthur D. Fisk, University of Illinois, Department of Psychology, Champaign, Illinois 61820. can then be made, with any differences being attributed to the experimental manipulation.

Associated with the increased recallability of the isolated list item is a decrement in recall of the adjacent items. This inhibitive spread of the effect of isolation was first reported by Jenkins and Postman (1948). It was suggested that the subjects' attention was attracted to the isolated item, which in turn led to less rehearsal time being allocated to the adjacent items. Tulving (1969) also reported an inhibitive spread of the effect of isolation. He was the first to report the operational similarity between the negative spread of the effect of isolation and clinical retrograde amnesia.

In the Tulving retrograde amnesia paradigm, a series of unrelated events is presented and recall is requested at termination of presentation. The experimental group is previously told to pay special attention to some word (such as the name of a president) and the exemplar occurs somewhere toward the middle of the list. The special words are called priority items. As compared with control performance, that is, recall performance of the subjects experiencing word lists that contain no priority items, recall of the word or words preceding the priority item is depressed. They are said to show retrograde amnesia. Saufley and Winograd (1970) demonstrated the same results without giving subjects special instruction to remember the critical item. Detterman and Ellis (1972) and Ellis, Detterman, Runcie, McCarver, and Craig (1971) showed that a von Restorff effect and retrograde amnesia could be produced in a somewhat different manner. Photographs of nude males and females were placed within lists of common line drawings. Substantial retrograde amnesia was produced when free recall was requested of subjects, but the effect was not observed with a recognition test. Shulz (1971) produced retrograde amnesia using Tulving's methodology and found that the use of 
a recognition test did not eliminate the amnesia. Detterman $(1975,1976)$ produced retrograde amnesia by greatly increasing the sound intensity of one word in each experimental list.

It seems clear that retrograde amnesia is a reproducible phenomenon that can be demonstrated using a wide variety of procedures; yet the cause is unresolved. Several attempts have been made to elucidate the locus of the retrograde amnesia phenomenon as first presented by Tulving in 1969. Following is a brief delineation of the major theories of the locus of retrograde amnesia.

Tulving (1969) suggested that the decrement of recall of the immediately preceding item (IPI) to the high-priority item (HPI) was due to interference in the processing of the IPI by the supervention of the HPI. He proposed that some version of the consolidation hypothesis could offer an explanation of retrograde amnesia. Tulving suggested that the locus of retrograde amnesia was in the encoding process. No decrease in recall of the immediately following item (IFI) to the HPI was observed, which was offered as additional support for his assumptions. Detterman and Ellis (1972) found that instructions to minimize rehearsal had no effect on retrograde amnesia. In addition, longer durations of the HPI increased the observed retrograde amnesia. Detterman (1975) instructed some of his subjects concerning the effects of the HPI and requested that the subjects develop an encoding strategy that would help them remember the IPI. His instructed subjects were unable to eliminate the effects of the HPI. Detterman (1976) found that he was able to eliminate retrograde amnesia using a cued recall test. The above mentioned findings, by Detterman (1975, 1976) and Detterman and Ellis (1972), led these researchers to the conclusion that the HPI affected the ability to retrieve the IPI from memory. Ellis et al. (1971) attempted to control rehearsal of the HPI by rate of presentation of the list items. They found that with a faster rate of presentation $(.75 \mathrm{sec})$ retrograde amnesia was not observed using a recognition test. Thus, they argued that retrograde amnesia was caused by an increase in the rehearsal of the HPI.

Although attempts have been made to alter the encoding environment under which subjects learn list items, no attempt has been made to systematically control the subjects' encoding environment. Therefore, the research strategy of the present experiment consisted of controlling the encoding strategy by the use of a semantic orienting task. A pleasant or unpleasant judgment was required of the subjects in the experimental conditions. This orienting task has been shown to facilitate recall of word lists relative to orienting tasks that do not require semantic processing (Hyde \& Jenkins, 1973).

If the locus of retrograde amnesia is in the output stage (retrieval), the use of an encoding strategy should not be effective in eliminating the effects of the HPI.
But if the HPI interferes with the optimal encoding of the IPI, then an appropriate encoding strategy should be effective in suppressing the priority effect (and, of course, retrograde amnesia should not be observed).

\section{METHOD}

\section{Subjects}

Three hundred introductory psychology students at The Ohio State University were utilized as subjects; participation partially fulfilled a course requirement. The subjects were tested in groups of five or fewer.

\section{Design}

The combination of the required tasks produced a 2 (orienting or no-orienting task) by 2 (priority instructions or no such instructions) factorial design. Three replications, with 25 subjects per condition for each replication, were conducted early, middle, and late in the academic quarter.

\section{Apparatus}

A Kodak carousel projector, Model $760 \mathrm{H}$, was used to project the words onto a white background. The rate of presentation, one word every $2 \mathrm{sec}$, was externally controlled by an electronic disk timer. The recall period was timed by a stopwatch.

\section{Materials}

Five different 15-noun item lists were presented to all subjects, the lists being the same for all subjects. Each list contained 15 independent categories, as indicated by the taxonomic category ratings of Collen, Wickens, and Daniele (1975). The words for each category were obtained from the norms of Battig and Montague (1969). For each category, words with the rank order of 1-5 inclusive were used as the criterion for word selection. ${ }^{1}$ Words of identical rank were placed in the same list (i.e., all words in List 1 had a rank order of 1 , all rank order 2 words were placed in List 2, etc.). The serial position of the priority item varied from the fifth to the ninth position across lists. Any given category occupied a given serial input position only once. A Latin square was used to control order of list presentation.

Each list began with the presentation of an asterisk, followed after $2 \mathrm{sec}$ by the first word of the list. A question mark came after the last word of each list, indicating an immediate written free recall test. After $45 \mathrm{sec}$ the recall period was terminated by the experimenter saying, "The time is up."

\section{Procedure}

The control subjects were told simply that they would see five lists with 15 words in each list and that, when a question mark appeared, they were to write as many words from the previous list as they could remember. In addition to the free recall instructions given the control group, the remaining subjects were given either priority instructions, orienting instructions, or both. The priority instructions consisted of telling the subjects to look for and remember a word from a certain category of words. With each list the category was changed. The categories actually used were: a profession, a unit of time, a vegetable, a kind of sport, and a city. The subjects in this condition were also told to write this "important" word first, if they were able to, before writing any other words. The subjects given orienting instructions were told to decide whether each word presented was pleasant, unpleasant, or neutral. These subjects were given $22 \times 28 \mathrm{~cm}$ paper with 15 numbered lines on each page. They were instructed to place a plus $(+)$ for a pleasant reaction, a minus (--) for an unpleasant reaction, or a zero (0) for a neutral reaction on the line corresponding to the 
word being presented. All subjects wrote the words they remembered on blank $22 \times 28 \mathrm{~cm}$ paper. One sheet of paper was used per list.

To summarize, there were four conditions. Subjects in the control condition received neither priority nor orienting instructions. Another condition involved priority instructions but no orienting task. The subjects in the two other conditions were given orienting instructions; one of these groups was not given priority instructions and the subjects in the remaining condition were given orienting task instructions and priority instructions.

\section{RESULTS}

A moderately strict criterion was used for scoring the data. For example, words were considered correct if the plural form was substituted for the singular. In addition, since the subjects were told not to worry about spelling, a word was considered correct if the response obviously corresponded to a list item (e.g., BLOSE substituted for blouse).

None of the statistical analyses concerning the replication effects reached significance $(p>.05)$, indicating that it made little difference when subjects were recruited for the experiment.

\section{High-Priority Items}

Figure 1 shows that a substantial von Restorff effect was produced by the priority instructions. That the item given priority was better remembered is shown by an analysis of variance which produced a significant main effect of priority instructions $[\mathrm{F}(1,288)=559.07$, $\mathrm{p}<.01]$.

\section{Immediately Preceding Items}

The data for examining the Tulving retrograde amnesia effect are provided by the recall performance of the IPI. The mean recall of the IPI is shown for all conditions in Figure 2. The relevant analysis for the conceptual purpose of the research is the interaction

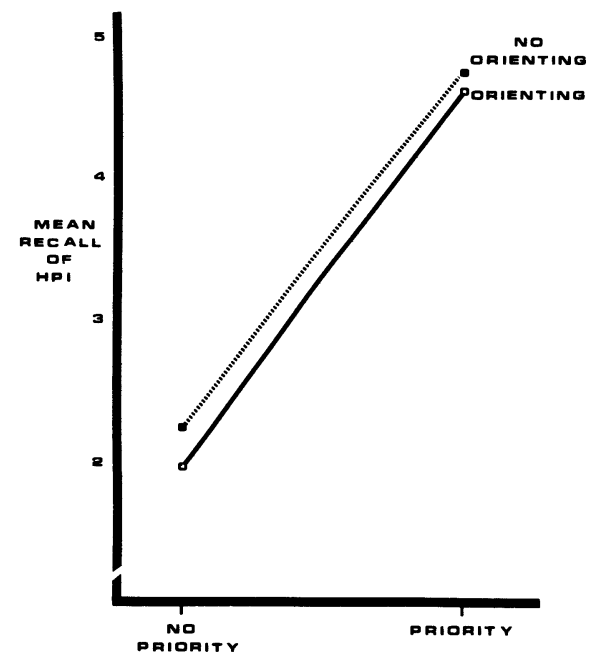

Figure 1. Mean recall of high-priority words across lists.

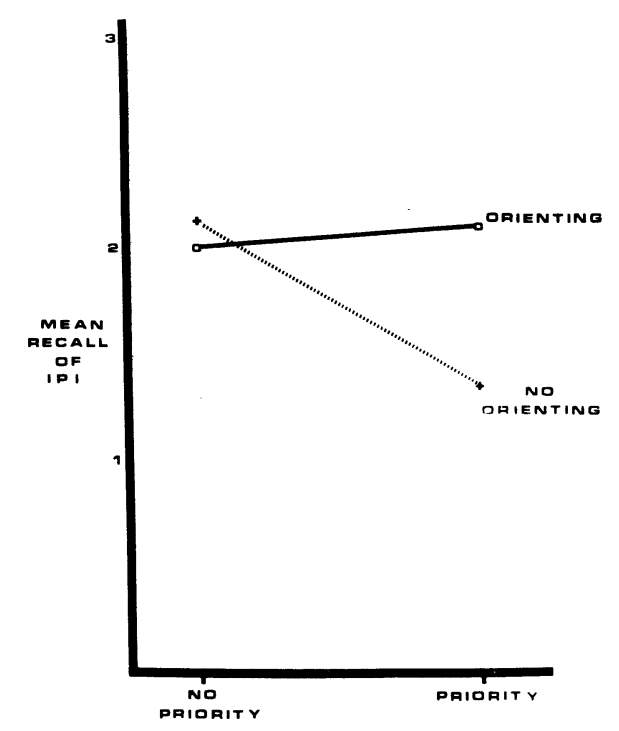

Figure 2. Mean recall, across lists, of all words immediately preceding the high-priority items.

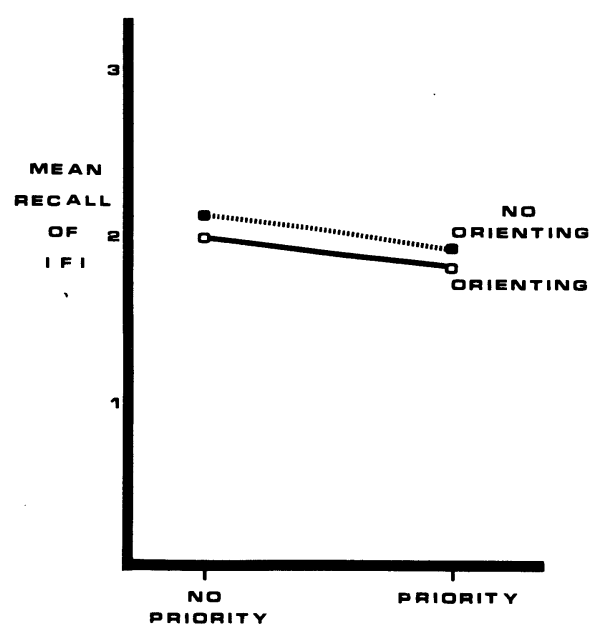

Figure 3. Mean recall, across lists, of all words immediately following the high-priority items.

between the priority and the orienting conditions. An analysis of variance revealed that this interaction was significant $[F(1,288)=11.75, \mathrm{p}<.01]$.

\section{Immediately Following Items}

In some instances researchers are interested in the recall of the immediately following items (IFI) to the HPI. If recall of the IFI is depressed, this is called anteriograde amnesia. Although the present experiment was not expressly designed to examine this type of amnesia, an analysis of variance was performed on the recall of the IFI. The data are shown for all conditions in Figure 3. The statistical analysis revealed a marginally significant main effect of priority $[F(1,288)=4.05, p<.05]$. The interaction was not significant $(F<1)$. The occurrence of a slight anterio- 
grade amnesia in the group performing the orienting task and given priority instructions was surprising. Perhaps the occurrence of the HPI is such a disruptive event that these subjects were not able, or willing, to perform the orienting task subsequent to the HPI. This is a testable hypothesis but one that cannot be resolved by the present design.

\section{DISCUSSION}

The present study has shown that an item in a list of common nouns can be made "outstanding" simply by telling subjects to look for and remember a word from a certain category of words. This isolation technique seems useful because any word in a list may be used as the isolate. In addition, the same list of words may be used for both the experimental and control conditions.

Retrograde amnesia is consistently associated with the outstanding word when subjects use their own methods of encoding to learn the word list; it is eliminated when subjects are required to use a semantic orienting task. Since retrograde amnesia is eliminated by controlled encoding, it is concluded that the normal priority effect is due to an interruption of the encoding of the item immediately preceding the HPI rather than being a retrieval problem. The locus of the Tulving retrograde amnesia effect seems unlikely to be in the retrieval stage since the retrieval environment was generally held constant in the present experiment.

It appears that the subjects given priority instructions and no encoding strategy only process the IPI to a peripheral level. It is hypothesized that these subjects do not process the IPI adequately before the onset of the HPI. In the absence of the task-appropriate processing, the ability to recall the IPI is suppressed. The data suggest that the subjects continue to encode the list items beyond the time in which the items are physically present. Further, it seems that the subjects normally continue processing a word at the time of the physical occurrence of the item immediately following it in the list. However, if this subsequent item is a word with high priority, the encoding of the item prior to it is disrupted or terminated. That is, the encoding of the IPI is hindered by the absence of normal overlapping encoding. It is assumed that subjects must process words to some "critical" level if the probability of recall is to be optimal. By requiring the subjects to use a semantic encoding strategy, the IPI reaches the "critical" level prior to the onset of the HPI. If the HPI takes away processsing time from the IPI, this is of little consequence once the given "critical" level of processing is achieved.

In sum, with concern to the primary purpose of the current research, the data support the position of an encoding deficit as the causal factor of the Tulving retrograde amnesia effect. The data do not support the retrieval position.

\section{REFERENCES}

Battig, W., \& Montague, W. Category norms for verbal items in 56 categories: A replication and extension of the Connceticut category norms. Journal of Experimental Psychology Monograph, 1969, 80(3, Part 2).

Collen, A., Wickens, D. D., \& Daniele, L. The interrelationship of taxonomic categories. Journal of Experimental Psychology: Human Learning and Memory, 1975, 1, 629-633.

Detterman, D. K. The von Restorff effect and induced amnesia: Production by manipulation of sound intensity. Journal of Experimental Psychology: Human Learning and Memory, 1975, 1, 614-628.

Detterman, D. K. The retrieval hypothesis as an explanation of induced retrograde amnesia. Quarterly Journal of Experimental Psychology, 1976, 28, 623-632.

Detterman, D. K., \& Ellis, N. R. Determinants of induced amnesia in short term memory. Journal of Experimental Psychology, 1972, 95, 308-316.

Ellis, N. R., Detterman, D. K., Runcie, D., McCarver, R. B., \& CRAIG, E. M. Amesia effects in short-term memory. Journal of Experimental Psychology, 1971, 89, 357-361.

Hyde, T. S., \& Jenkins, J. J. Recall for words as a function of semantic, graphic, and syntactic orienting tasks. Journal of Verbal Learning and Verbal Behavior, 1973, 12, 471-480.

Jenkins, W. O., \& Postman, L. Isolation and "spread of effect" in serial learning. American Journal of Psychology, 1948, 61, 214-221.

SAUfley, W. H., \& WinogRAD, E. Retrograde amnesia and priority instructions in free recall. Journal of Experimental Psychology, 1970, 85, 150-152.

SHULz, L. S. Effects of high-priority events on recall and recognition of other events. Journal of Verbal Learning and Verbal Behavior, 1971, 10, 322-330.

Tulving, E. Retrograde amnesia in free recall. Science, 1969, 64, $88-90$.

W Allace, W. P. Review of the historical, empirical, and theoretical status of the von Restorff phenomenon. Psychological Bulletin, 1965, 63, 410-424.

\section{NOTE}

1. The criterion for word selection from the category of CITIES was the first five single-word cities encountered in the Battig and Montague (1969) norms. That is, New York was not an appropriate word.

(Received for publication March 28, 1979.) 